\section{The power of collaborative student-led workshops}

Sir, I feel it is fair to say that although the current pandemic has changed our normal way of working, the adaptability of dental healthcare professionals and students has allowed dentistry to continue, albeit in a new environment. One such impact was the implementation of social distancing measures, forcing lectures and workshops onto an online delivery. However, this may have presented as a silver lining, for it has afforded better connections and engagements between individuals at a global and local level, improving communication and interactions between dental professionals. ${ }^{1}$

During the height of the pandemic in March 2021, I and several other students took part in a new joint venture between the periodontology department at the Academic Centre for Dentistry Amsterdam (ACTA) and King's College London (KCL). The session presented by the students at KCL and ACTA, allowed for thoughts and deliberation on the different views, and clinical training between two of the world's leading dental schools. ${ }^{2}$ The workshop aimed to explore the differences between a small cohort of undergraduate/postgraduate dental students from both universities on their approach to a periodontal clinical case. Two weeks before the workshop both student groups were given the same postgraduate clinical case, and each group were asked to prepare suggested diagnoses, prognosis, treatment plan and expected outcomes for the patient. The major issues that were diagnosed in some of the teeth included furcation wall defects, infra bony defects, horizontal bone defects, pockets greater than $5 \mathrm{~mm}$, and the presence of periapical pathology. While in normal circumstances the presentations would have taken place in a packed lecture theatre, social distancing and travel restrictions meant the event was forced to take place remotely over Microsoft Teams.

After the presentation, both student groups were allowed to discuss with one another and explain why the treatment options they chose were best for the patient. ACTA students varied in their approach to the clinical examination of aetiological factors contributing to periodontal disease; a pie chart was made using quantitative measures of a patient's stress levels, presenting a generic multi causality model of periodontitis. ${ }^{3}$ Such approach allowed more focus on the specific modifiable aetiological factors to better predict the prognosis of teeth and create a more effective treatment plan. For periodontal therapies that are labelled as aerosol-generating procedures, such as furcation therapy, the KCL group emphasised the use of micromotors limited to speeds of less than 60,000 rpm, eliminating potentially infectious aerosols created and reducing cross-contamination. ${ }^{4}$ Furthermore, if micromotors were not available, the use of "fallow time" between appointments is implemented to allow unavoidable aerosols to settle during certain procedures such as ultrasonic scaling, but can only occur in closed single chair clinics. However, at ACTA fallow times and micromotors were not implemented, and instead the use of prophylactic mouthwash of hydrogen peroxide and chlorhexidine, which can reduce transmission of COVID-19 through aerosols during oral procedures. ${ }^{5}$

This new way of learning provided insight into each dental school's unique way of treating patients. The workshop was very beneficial to both European neighbours, in giving a glimpse into each other's dental schools. We can learn a lot from the differences in the way we diagnose, predict prognosis and effectively treat patients. I wish for more dental schools to put forward more of these learning opportunities for dental students in the future.

\section{R. Lee, London}

\section{References}

1. Quinn B, Field J, Gorter R, Akota I, Manzanares MC, Paganelli $C$, etal COVID-19: the immediate response of European academic dental institutions and future implications for dental education. Eur J Dent Educ 2020; 24: 811-814.

2. QS World Ranking. QS World University Rankings by Subject 2021: Dentistry. Top Universities. 2021 Available online at: www.topuniversities.com/university-rankings/ university-subject-rankings/2021/dentistry (Accessed June 2021).

3. Loos B, Van Dyke T. The role of inflammation and genetics in periodontal disease. Periodontology 2000 2020; 83: 26-39.

4. Sergis A, Wade W, Gallagher J, Morrell A, Patel S, Dickinson C et al. Mechanisms of Atomization from Rotary Dental Instruments and Its Mitigation. J Dent Res 2020; 100: 261-267.

5. Vergara-Buenaventura A, Castro-Ruiz C. Use of mouthwashes against COVID-19 in dentistry. Br J Oral Maxillofac Surg 2020; 58: 924-927.

\section{Quality ratings of dental radiographs}

Sir, I note with interest the paper on clinical governance by Mistry. ${ }^{1}$ Mistry used the audit of image quality of dental radiographs as an example of an audit. She mentioned the guidance from the Faculty of General Dental Practice (UK) was that no less than $70 \%$ of radiographs should be categorised as grade 1 and no more than $10 \%$ should be categorised as grade $3 .^{2}$ However, the targets for the subjective image quality rating were changed last year. Therefore, the target figures quoted by Mistry were out of date. ${ }^{1}$

\section{'For digital imaging, no less than $95 \%$ of dental radiographs should be rated as 'A' and no greater than $5 \%$ as ' $N$ "}

Since the second edition of Guidance Notes for Dental Practitioners on the Safe Use of $X$-ray Equipment was published in October 2020, the use of three-point scale for the subjective quality rating of dental radiographs has been replaced by a two-point scale. The images are now rated either 'diagnostically acceptable' ('A') or 'not acceptable' ('N'). For digital imaging, no less than $95 \%$ of dental radiographs should be rated as 'A' and no greater than $5 \%$ as ' $\mathrm{N}$ '. For film imaging, the targets are slightly lower - no less than $90 \%$ should be rated as 'A' and no greater than $10 \%$ as ' $\mathrm{N}$ '. The use of a two-point scale is now recommended for all forms of dental radiography and dental cone-beam computed tomography imaging.

\section{A. Yeung, Bothwell, UK}

\section{References}

1. Mistry B. Clinical Governance: $A$ simple guide. BDJ Student 2021; 28: 11

2. Faculty of General Dental Practice (UK). Selection Criteria for Dental Radiography. 9.2 Ideas for audit developing local guidelines. February 2018. Available at: https://www.fgdp.org.uk/selection-criteria-dentalradiography/92-ideas-audit-\%E2\%80\%93-developinglocal-guidelines (accessed May 2021)

3. Public Health England (PHE) and Faculty of General Dental Practice (UK) [FGDP (UK)]. Guidance Notes for Dental Practitioners on the Safe Use of $X$-ray Equipment. 2nd ed. London: PHE and FGDP (UK), 2020. 